\title{
Educação em saúde no trabalho de enfermeiras em Santarém do Pará, Brasil
}

\author{
Health education in the job of nurses in Santarém of Pará, Brazil \\ Educación en salud en el trabajo de enfermeras en Santarém del Pará, Brasil
}

\begin{abstract}
Maura Cristiane e Silva Figueira', Tânia Maria Coelho Leite", Eliete Maria Silva'II
' Faculdades Integradas do Tapajós, Departamento de Saúde Coletiva. Santarém-PA, Brasil.

" Universidade Estadual de Campinas, Colégio Técnico de Campinas. Campinas-SP, Brasil.

III Universidade Estadual de Campinas, Faculdade de Ciências Médicas,

Departamento de Enfermagem. Campinas-SP, Brasil.
\end{abstract}

Submissão: 14-07-2010 Aprovação: 27-07-2012

\section{RESUMO}

Trata-se de pesquisa qualitativa, cujos objetivos foram analisar os saberes e as práticas educativas realizadas por enfermeiras em unidades de Saúde da Família, em Santarém-PA, Brasil, e a utilização da educação em saúde no processo de trabalho. Realizamos entrevistas semiestruturadas com 15 enfermeiras e observação das suas práticas educativas. Da análise de conteúdo emergiram os temas: concepções sobre educação em saúde; práticas educativas no processo de trabalho; tendência à educação popular. A maioria absoluta das enfermeiras é especialista em saúde da família, contudo referem carência do conteúdo teórico da educação em saúde em sua formação. O modelo tradicional predomina nas concepções e nas práticas. O processo de trabalho é predominantemente organizado a partir dos programas ministeriais. Nas ações de saúde, pode-se reconhecer uma discreta tendência à educação popular, com tentativas de reorientar as práticas educativas, estabelecendo parcerias com outros cuidadores e lideranças da comunidade.

Descritores: Educação em Saúde; Enfermagem; Programa Saúde da Família.

\begin{abstract}
This qualitative study aimed to analyze the knowledge and educational practices of nurses in the Family Health Units, in Santarém-PA, North of Brazil, and their utilization of health education tools within the labour process. We conducted semi-structured interviews and observation of educational activities of 15 nurses. From the content analysis, the following themes emerged: conceptions of health education; educational practices within the work process; and a trend to the Popular Education theoretical framework. Despite most of the nurses were Family Health specialists, they mentioned a gap in their professional education in terms of theoretical knowledge about health education. The traditional models were predominant in the conceptions and practices. The labour process is strongly based on Ministry of Health's programs. It was possible to recognize a discrete trend to Popular Education, with attempts to a reorientation of their educational practices, establishing partnerships with other care providers and community leaderships.

Key words: Health Education; Nursing; Family Health Program.
\end{abstract}

\section{RESUMEN}

Investigación cualitativa cuyos objetivos fueron analizar los conocimientos y las prácticas educativas realizadas por los enfermeros en las unidades de salud de la familia en Santarém, Brasil y el uso de la herramienta de educación en salud en el proceso de trabajo. Realizamos entrevistas semi estructuradas con 15 enfermeras y observación de sus prácticas educativas. De la análisis de contenido ha surgido los temas: concepciones de la educación en salud; prácticas educativas en lo proceso de trabajo y tendencia a la educación popular. La mayoría absoluta de las enfermeras es especialista en salud de la familia, aunque refieran carecimiento de la teoría sobre la educación en su formación. El modelo tradicional domina las concepciones y las prácticas. El proceso de trabajo predominante se basa en programas ministeriales. En las acciones sanitarias existe una moderada tendencia para la educación popular, con intentos de reorientar las prácticas educativas, estableciendo participaciones com otros cuidadores e líderes comunitarios.

Palabras clave: Educación para la Salud; Enfermería; Programa de Salud Familiar. 


\section{INTRODUÇÃO}

No contexto da saúde da família, existem estudos acerca das práticas educativas em enfermagem reportando-se a diversas regiões do país ${ }^{(1-4)}$, entretanto, na região Amazônica tais estudos são escassos.

A região tem peculiaridades relativas às ações em saúde de outros locais, especialmente pelas questões geográficas e culturais. Suas grandes distâncias, padrão de concentração populacional irregular e insuficiência de vias e meios de transporte resultam em dificuldades no acesso a bens e serviços públicos, sendo as ações de saúde um exemplo destes.

O Município de Santarém é o maior município da região oeste do Pará (PA), localizado na região do Baixo Amazonas, na margem direita do rio Tapajós, em sua confluência com o rio Amazonas. Conforme dados do Instituto Brasileiro de Geografia e Estatística de 2008, conta 282.707 habitantes, com densidade demográfica de 11,68 hab./ $\mathrm{Km}^{2} \mathrm{e}$ área territorial de $22.887 \mathrm{~km}^{2}$.

A implantação do Programa de Saúde da Família (PSF) no Estado ocorreu a partir do ano de 1994, nos municípios de Bragança (duas equipes) e Redenção (três equipes) ${ }^{(5)}$. No final de 2009, o Pará tinha 880 equipes de PSF, com cobertura populacional de $39,7 \%{ }^{(6)}$.

A primeira equipe de saúde da família em Santarém foi implantada em 1998 como experiência piloto em uma comunidade rural, de acesso terrestre, chamada de Mojuí dos Campos. Outras equipes foram implantadas em bairros da zona urbana e até o ano de 2006 totalizaram 27 equipes, de acordo com o Programa de Expansão e Consolidação da Saúde da Família, tendo uma cobertura de 30\% da população, aproximadamente ${ }^{(6)}$.

Desde maio de 1998, o Município de Santarém habilitou-se à Gestão Plena do Sistema Municipal de Saúde, de acordo com a Norma Operacional Básica - NOB/SUS/96 e foi posteriormente adequada à Norma Operacional de Assistência à Saúde - NOAS/2001/02. A rede de serviços assistenciais compõe-se de cinco hospitais privados conveniados, um hospital municipal, um hospital regional do oeste do Pará, quatro centros de atendimento 24 horas, serviço de atendimento móvel de urgência, duas Ambulanchas (lanchas utilizadas para remoção de urgência/emergência das comunidades ribeirinhas), seis unidades especializadas de referência, seis laboratórios públicos, 38 centros de saúde, 37 postos de saúde e 27 equipes saúde da família, sendo 21 urbanas em 12 bairros e seis rurais em sete comunidades. O número de enfermeiros na atenção primária é de 52 profissionais, destes 27 trabalham na Estratégia Saúde da Família (ESF), nove em unidades básicas e 16 no Programa de Agentes Comunitários de Saúde (PACS) ${ }^{(7)}$.

As práticas educativas em saúde, realizadas por enfermeiras, compõem a prática social da enfermagem e caracterizam-se como instrumentos fundamentais no processo de trabalho em saúde. Dessa forma, estudar estas práticas no contexto das unidades de saúde da família em Santarém, no Pará, evidencia a realidade de um Estado amazônico que apresenta potencialidades a serem valorizadas. Utilizamos o referencial do Processo de Trabalho para compreendê-las.
As práticas de saúde são compreendidas como trabalho, pois possuem uma teleologia, isto é, atendem a um fim, a um objetivo. O processo de trabalho é sempre intencional, ou seja, transforma o "antes", mediado por gasto de energia, em um "depois" idealizado, com vistas a atender uma finalidade histórica e social. Essa energia consiste no conjunto de instrumentos e qualidades humanas naturais (potencialidades) que podem ser ativadas pela força de trabalho para realizar transformações na natureza ${ }^{(8)}$.

As necessidades variam de acordo com o contexto histórico e social em que as pessoas estão inseridas. Portanto, os carecimentos, transformados em finalidades, guiam todos os processos de trabalhos, não somente do trabalhador individual, mas sim do grupo em que ele vive. Com base nisso, procuramos compreender essa dinâmica no Município.

Na saúde, o processo de trabalho apresenta especificidades, sendo que o ser humano é o agente e também o objeto do trabalho em saúde e deve ser reconhecido de maneira objetiva e, também, subjetiva (desejos, emoções, paixões, repulsas, ódios etc. $)^{(8)}$.

A enfermagem é considerada como trabalho, buscando reconhecer sua finalidade, tecnologias, objetos e agentes e a organização tecnológica da sua prática ${ }^{(9)}$. Os instrumentos de trabalho são construídos historicamente pelos sujeitos, e no trabalho em enfermagem e em saúde encontramos tanto instrumentos materiais, quanto intelectuais, tais como os saberes técnicos que fundamentam a ação realizada ${ }^{(10)}$.

O campo da educação em saúde tem sido, desde a década de 1970, profundamente repensado, verificando-se um relativo distanciamento das ações impositivas, características do discurso higienista. Há uma ampliação da compreensão sobre o processo saúde-doença, que, saindo da concepção restrita do biologicismo, passa a ser concebido como resultante da inter-relação causal entre fatores sociais, econômicos e culturais. Neste momento, as práticas pedagógicas persuasivas, a transmissão verticalizada de conhecimentos, refletindo o autoritarismo do educador para com o educando e a negação da subjetividade nos processos educativos são passíveis de questionamentos ${ }^{(4)}$. É também neste contexto que surge a preocupação com o desenvolvimento da autonomia, com a constituição de sujeitos sociais que reivindicavam os seus interesses $^{(11)}$.

Na perspectiva da Educação Popular em Saúde, prioriza-se o envolvimento da população, rompendo com a verticalidade da relação profissional-usuário. Valorizam-se as trocas interpessoais, as iniciativas, o diálogo e buscam-se a explicitação e a compreensão do saber popular ${ }^{(11)}$. Esta forma contrapõe-se à passividade usual das práticas educativas tradicionais. O usuário é reconhecido como sujeito portador de um saber sobre o processo saúde-doença-cuidado capaz de estabelecer uma interlocução dialógica com o serviço de saúde e desenvolver uma análise crítica sobre a realidade e o aperfeiçoamento das estratégias de luta e enfrentamento ${ }^{(4)}$.

A convivência com equipes de saúde da família em municípios da região Amazônica nos fez questionar o trabalho das enfermeiras em relação às práticas educativas: quais eram os saberes dessas profissionais sobre Educação em Saúde e de 
que maneira as práticas educativas se apresentavam em seus processos de trabalho.

Assim, traçamos como objetivos deste estudo: analisar os saberes e práticas educativas realizadas por enfermeiras em unidades de Saúde da Família, em Santarém, no Pará, Brasil.

\section{PERCURSO METODOLÓGICO}

Para a compreensão dos saberes e das práticas educativas realizadas no cotidiano das enfermeiras e a percepção deste instrumento no processo de trabalho, utilizamos uma abordagem metodológica para captar os significados, o conhecimento e atitudes que configuram o comportamento destas trabaIhadoras. Optamos pela pesquisa com abordagem qualitativa e descritiva(12), com estudo de campo nas unidades de saúde da família da área urbana do Município.

A coleta de dados foi realizada no período de outubro a dezembro de 2009, utilizando entrevistas semiestruturadas com as enfermeiras com mais de um ano de trabalho e observação sistemática das práticas educativas.

O projeto foi aprovado pelo Comitê de Ética em Pesquisa da Faculdade de Ciências Médicas da Unicamp, no mês de março/2009, sob o parecer $n^{\circ} 127 / 2009$, de acordo com a resolução 196/96 do Conselho Nacional de Saúde (CNS). A coleta de dados ocorreu após a autorização da Secretaria Municipal de Saúde de Santarém e assinatura do Termo de Consentimento Livre e Esclarecido. Garantimos o anonimato dos sujeitos pela atribuição de codinomes relacionados a qualidades próprias, escolhidas pelos mesmos. As entrevistas foram gravadas e transcritas e as observações registradas em roteiro.

Para a análise dos dados empíricos, utilizamos a análise do conteúdo ${ }^{(12)}$. Realizamos leituras exaustivas das entrevistas e das observações deixando-nos impregnar pelo conteúdo, considerando os objetivos e os referenciais teóricos, identificando os temas centrais e aspectos relevantes.

\section{RESULTADOS E DISCUSSÕES}

Das 21 Unidades de Saúde da Família participaram 15 enfermeiras, pois, no período da coleta de dados, três estavam em férias, uma em licença maternidade, uma tinha menos de um ano de trabalho e uma estava em treinamento, conforme tabela a seguir.

Foram observadas atividades grupais, consulta de enfermagem, visita domiciliária, palestras com gestantes e o acompanhamento do peso de crianças na micro área. A partir dos dados compilados, construímos as seguintes categorias temáticas: concepções das enfermeiras sobre educação em saúde; práticas educativas e o processo de trabalho; tendência à educação popular nas práticas educativas.

\section{Concepções das enfermeiras sobre educação em saúde}

A compreensão das enfermeiras sobre educação em saúde apresenta algumas características do modelo hegemônico, pautado no modelo sanitário prescritivo, com ênfase no controle das doenças e enfoque na intervenção e controle do comportamento das pessoas ${ }^{(13-14)}$. As citações sobre "educar",
Tabela 1 - Caracterização das enfermeiras entrevistadas, Equipes de Saúde da Família urbanas de Santarém-PA,

Brasil, 2009.

\begin{tabular}{c|c|c}
\hline Características & Atributos & $\mathbf{n}$ \\
\hline \multirow{2}{*}{ Idade (em anos) } & $30-39$ & 04 \\
\cline { 2 - 3 } & $40-49$ & 10 \\
\hline \multirow{2}{*}{ Tempo de formadas (em anos) } & $1-10$ & 05 \\
\cline { 2 - 3 } & $>10$ & 10 \\
\hline \multirow{2}{*}{$\begin{array}{c}\text { Tipo da instituição } \\
\text { de formação }\end{array}$} & Privada & 13 \\
\cline { 2 - 3 } Especialização & Pública & 02 \\
\cline { 2 - 3 } & Saúde da Família & 14 \\
\hline \multirow{3}{*}{$\begin{array}{c}\text { Tempo de trabalho na Atenção } \\
\text { Primária (em anos) }\end{array}$} & $01-04$ & 01 \\
\cline { 2 - 3 } & $05-08$ & 0 \\
\cline { 2 - 3 } & $09-12$ & 01 \\
\cline { 2 - 3 } & $13-16$ & 10 \\
\hline \multirow{3}{*}{$\begin{array}{c}\text { Tempo de trabalho no PSF } \\
\text { (em anos) }\end{array}$} & $01-04$ & 04 \\
\cline { 2 - 3 } & $05-08$ & 08 \\
\cline { 2 - 3 } & $09-12$ & 03 \\
\cline { 2 - 3 } & $13-16$ & 0 \\
\hline \multirow{2}{*}{\begin{tabular}{c} 
Vínculo empregatício \\
\hline
\end{tabular}}
\end{tabular}

Fonte: Dados da pesquisa

"orientar", "prevenir" e "informar" são muito presentes e quase unânimes nas definições externadas pelas enfermeiras como podemos perceber nas entrevistas:

...o próprio nome já diz pra gente que é educar as pessoas pra ter e manter saúde. (Estrela)

Pra mim é o meio que se obtém para orientar as pessoas no sentido de promover a qualidade de vida da população. (Caridosa)

Ah, educação em saúde é trabalhar na prevenção, né, na prevenção de doenças, orientar, e é basicamente isso. (Tranquila)

Algumas enfermeiras referiram preocupação com a participação da população como agente ativa no processo saúde-doença. Veem as ações de educação em saúde como oportunidade para desenvolver nas pessoas a consciência acerca da importância da co-responsabilização de todos os envolvidos na promoção e proteção da saúde, tanto o profissional, quanto os indivíduos e a comunidade. A percepção de que deve haver troca de saberes, de experiências, de compreensão, permeiam o discurso:

Educação em saúde é troca de experiência, você pode até sugerir, conversando, incentivar as pessoas [...]. Você aprende muito com a comunidade, aprende muito conversando, aprende muito ouvindo e dividindo os conhecimentos. (Experiente) 
Nas respostas, identificamos um sentimento de preocupação com a participação das pessoas nas práticas educativas no processo de trabalho, para proporcionar oportunidades de envolvimento e empoderamento, com o objetivo de mudanças com vistas à autonomia, sem coerção ou obrigatoriedade, características do modelo dialógico da educação popular em saúde.

Nessa perspectiva, busca-se romper com o modelo normatizador, propondo-se um movimento contínuo de diálogo e troca de experiências, compreendendo o outro como sujeito detentor de conhecimentos e não mero receptor de informações ${ }^{(15)}$. Práticas educativas mais participativas, construindo saberes e práticas junto aos usuários de saúde, com fortalecimento de diálogos, negociação entre os diversos atores, com conhecimento dos seus padrões culturais são capazes de reorientar o fazer em saúde, mais integrado à vida local e com um cuidar de enfermagem na perspectiva da integralidade ${ }^{(16)}$.

Sobre em quais momentos da sua formação haviam tido discussões voltadas para educação em saúde, as enfermeiras salientaram as práticas realizadas nos estágios como, por exemplo, "o dia de fazer palestras e orientações para as pessoas", porém estas discussões não se articulavam com aulas teóricas; o processo pedagógico, questões sociais, econômicas e culturais não foram abordadas.

\section{Práticas educativas e o processo de trabalho nas unidades de saúde da família}

Percebemos que a maneira de organização do trabalho nas unidades de saúde da família permite às enfermeiras a adequação dos instrumentos para organizar o trabalho. A enfermeira tem autonomia para organizar o trabalho com a equipe. Geralmente, utiliza um cronograma semanal das atividades e diariamente estabelece uma rotina de atendimentos na unidade, de acordo com os programas ministeriais. Pudemos observar que ocorre sobrecarga de trabalho devido à centralização de atendimentos para a enfermeira e também, pela equipe reduzida na unidade. Uma dificuldade enfrentada pela enfermagem na saúde da família é "a sobrecarga de trabalho pela demanda e pela equipe desfalcada, o que tem gerado desmotivação para a equipe e insatisfação com o trabalho"(17).

As práticas educativas são realizadas em momentos variados. As entrevistadas foram unânimes em citar: os grupos mensais de diabéticos, hipertensos e de grávidas e grupos semanais de mulheres, para a coleta do exame preventivo do câncer, e de mães, no programa de crescimento e desenvolvimento de crianças e a consulta individual de enfermagem. As visitas à escola e à creche do bairro também foram citadas, bem como, as visitas domiciliárias realizadas geralmente em dois dias da semana. Além disso, mensalmente, os agentes comunitários verificam o peso das crianças por micro área. Todos esses momentos foram citados como oportunidades para realizar atividades educativas. Portanto, no processo de trabalho a educação em saúde está presente, segundo o relato das enfermeiras. Porém, percebemos algumas divergências na maneira de utilização de tal instrumento, com um enfoque mais tradicional e outro mais dialógico.
Assim, nós fazemos na realidade uma espécie de cronograma, né. A gente faz um cronograma anual e a gente distribui em meses as atividades, então, nós planejamos pro ano inteiro fazer educação em saúde nas escolas, na creche do bairro, nos grupões de diabéticos e hipertensos, e na própria unidade de saúde com palestras [...] (Perseverante)

Eu gosto [...] é um trabalho que você ensina e aprende com eles, o trabalho do PSF. [...] você vai aprendendo muito com eles e quanto mais você aprende, mais você quer fazer, entendeu? (Persistência)

Todos os atendimentos [...] a gente tem que trabalhar a educação [...] e às vezes apraza pra verificar o cliente em domicílio, como é a vivência dele, como é que está a família, então muitas das vezes a gente acaba indo verificar essa família 'in loco', na residência. (Caridosa)

Cotidianamente são realizadas campanhas educativas, seguindo a programação do Ministério da Saúde. Como exemplo, podemos citar a campanha para detectar casos de tuberculose, de hanseníase, a programação do aleitamento materno, as campanhas de coleta do exame preventivo do câncer, as campanhas de combate à dengue, enfim, práticas executadas pelos trabalhadores, de acordo com a determinação da Secretaria de Saúde em que o profissional altera seu processo de trabalho para cumprir as exigências.

Dessa forma, a relação com a comunidade permanece utilitarista, o que ocorre quando as atividades são conduzidas no sentido de garantir mobilização dos indivíduos para as campanhas $^{(18)}$.

Dentre as entrevistas, chamou a atenção o relato de uma enfermeira sobre o compartilhamento de saberes com a equipe, visando, segundo ela, à descentralização dos atendimentos e ao apoio na organização e na realização do processo de trabalho:

Eu já ensinei pra elas [pras técnicas] a ler o exame, entender o que tá alterado, [...]. Eu 'dividi' o que eu sei com a equipe pra elas me ajudarem. Tem vezes que elas chegam e dizem: 'enfermeira olha essa hemoglobina baixa!'. Não é bonito isso? Ou então: 'olha a urina dessa grávida!' [...] e qualquer alteração elas reconhecem e me passam.[...] $A$ técnica, hoje, pega os encartes e orienta as mães, as grávidas e isso é muito bom! (Organizada)

Os saberes da enfermagem compõem um dos momentos do processo de trabalho, ou seja, são instrumentos que permitem a aproximação e a transformação do objeto da enfermagem para alcançar a sua finalidade $\mathrm{e}^{(9-10)}$. O compartilhamento dos saberes na equipe promove condições para a satisfação das necessidades das pessoas que procuram a unidade e que, portanto deve ser a finalidade da equipe de saúde da família, e não somente da enfermeira.

Alguns profissionais questionam o direcionamento dado às suas atividades e às determinações institucionais, tendo uma 
forma de organizar o trabalho de maneira criativa, abrindo espaços para a equipe e saindo da impessoalidade.

A educação está presente em todas as relações que se estabelecem entre os trabalhadores de saúde e os usuários. No processo de trabalho observado, a valorização dada à educação em saúde aparece em vários momentos. Cada profissional, ao dar um significado à prática educativa, revela uma forma de ser educador, suas práticas têm relação direta com as suas representações sobre o educar - "só é educador o profissional que tem consciência dessa possibilidade e sobre ela trabalha"(19).

A enfermeira deve ter o entendimento e a sensibilidade de ser educadora, deve ter intencionalidade na prática educativa para a satisfação das necessidades históricas e sociais, buscando a participação das pessoas envolvidas. Nesta perspectiva, a compreensão de que todo profissional de saúde é um educador em potencial é condição essencial à sua prática, bem como, reconhecer-se enquanto sujeito no processo educativo e o reconhecimento dos usuários enquanto sujeitos em busca de sua autonomia ${ }^{(11)}$.

A dimensão educativa foi sempre enfatizada no trabalho de enfermagem, mais que em outras profissões, e mesmo reconhecendo-se como educador, a ação educativa tende a ser vista como uma ação técnica, componente ou adicional ao conjunto de práticas profissionais, em lugar de uma dimensão inerente à prática profissional| ${ }^{(13)}$.

\section{Tendência à educação popular nas práticas educativas}

Algumas situações vivenciadas pelas enfermeiras remetem à educação popular, entretanto elas não têm clareza desta fundamentação teórica. De acordo com os relatos e observações, identificamos que o trabalho executado vai além do enfoque técnico da enfermagem e que a escuta, o diálogo e o vínculo estão presentes nas situações do cotidiano.

Percebemos que a experiência de sete das enfermeiras, como por exemplo, no Programa de Agentes Comunitários de Saúde, enquanto instrutor/supervisor, proporcionando melhor conhecimento das condições de vida das pessoas, do local onde moram, da organização comunitária, dos hábitos e costumes, favorece, na maioria dos casos, a sensibilidade para a priorização de condutas planejadas em conjunto entre usuários e profissionais.

Nas observações de campo, verificou-se que as enfermeiras buscam avaliar as reais necessidades das pessoas, mencionam preocupação em não impor assuntos e realizar as atividades de acordo com as demandas percebidas. Ao atender, nos grupos educativos, pessoas da zona rural e de outras áreas adscritas na saúde da família em outras equipes, por conhecer a distância, as dificuldades sofridas e peculiaridades do local em que moram, priorizam o atendimento. Entretanto, esta percepção não é unânime entre as enfermeiras.

Antes da existência do serviço, a comunidade resolvia seus problemas de saúde contando com os práticos, as parteiras, as mães, as pessoas que utilizavam ervas, os professores, entre outros. Pessoas que, empiricamente, através de uma cultura aprendida informalmente, eram os mais capacitados para cuidar $^{(20)}$.
No território das unidades de saúde de Santarém, há pessoas que realizam tais práticas populares de cuidado como benzedeiras, curandeiros, parteiras e "puxadores", que realizam manobras durante a gravidez para posicionar o bebê ou realizam massagens para alívio de dores e "mau jeitos".

Percebemos o interesse de algumas enfermeiras em buscar entrosamento entre as diferentes práticas, realizando reuniões com os representantes de igrejas, associação de moradores, benzedeiras, parteiras e outros para divulgar e apoiar seu processo de trabalho, sem entrar em conflito com as diversas formas de cuidados à saúde:

[...] então a gente reuniu com a comunidade, o presidente do bairro, da igreja, pra tá falando das nossas atividades e que o trabalho deles também é muito importante [...]. As parteiras, as benzedeiras, também convidamos. Até veio uma senhora de umbanda. A gente reuniu [...] pra trabaIhar em parceria [...] que 'o importante é a saúde da pessoa que procura'[...]. (Responsável)

A busca de parcerias para a realização do trabalho também é uma das estratégias utilizadas para melhorar os serviços das unidades de saúde. Algumas enfermeiras relataram ser extremamente importante buscar parceiros nos bairros, tais como a associação de moradores, igrejas católica e evangélica, escolas, creches, empresas privadas, organizações não governamentais, instituições de ensino na área de saúde dentre outros:

E a gente tem outros parceiros também no bairro, e a gente faz sempre esse trabalho conjunto, é muito bom! (Perseverante)

As práticas educativas nesses locais são evidentes e estimuladas pela própria comunidade, que participa no planejamento das ações, bem como na sua realização. Muitas enfermeiras relatam que, apesar das dificuldades encontradas, surpreendem-se com a aceitação, com a adesão das pessoas ao trabalho educativo e percebem o quanto ser educador Ihes dá credibilidade, confiança, tornando-os referência para os atendimentos, esclarecimentos, confidências, apoio emocional. Enfim, vínculos afetivos são estabelecidos proporcionando maior compreensão dos problemas e colaboração para a resolução dos mesmos.

\section{CONSIDERAÇÕES FINAIS}

Partindo do objetivo geral deste estudo e dos referenciais teóricos do Processo de Trabalho e da Educação Popular em Saúde, identificamos o potencial presente na enfermagem para propor mudanças no seu processo de trabalho e, com isso, a satisfação das necessidades de saúde.

As enfermeiras devem incentivar as pessoas a se envolverem mais com a educação em saúde nas comunidades, pois a participação conjunta com troca de saberes nas ações educativas fortalece as relações, forma vínculos, confiança e é fundamental na qualificação do processo de trabalho da enfermagem em saúde coletiva. 
As discussões sobre estes temas no contexto da estratégia saúde da família devem ser estimuladas com o objetivo de organizar o processo de trabalho das equipes e da enfermagem e aprimorar a utilização deste potente instrumento, a educação em saúde, nos moldes da educação popular, já presente em algumas atividades.

Salientamos a importância da realização de encontros entre as equipes para compartilhar experiências, além de uma maior proximidade da coordenação municipal apoiando a realização das práticas educativas. E, por fim, a necessidade de se divulgar estas experiências, ressaltando as práticas educativas como instrumentos fundamentais no processo de trabalho em saúde e na enfermagem.

\section{AGRADECIMENTOS}

Agradecemos o financiamento recebido da Fundação e Instituto para o Desenvolvimento da Amazônia (FIDESA) e o apoio da Secretaria Municipal de Saúde de Santarém-PA para a realização desta pesquisa.

\section{REFERÊNCIAS}

1. Melo G, Santos RM, Trezza MCSF. Entendimento e práticas de ações educativas de profissionais do programa de saúde da família de São Sebastião-AL: detectando dificuldades. Rev Bras Enferm 2005; 58(3):290-5.

2. Heringer A, Ferreira VA, Acioli S, Barros ALS. Práticas educativas desenvolvidas por enfermeiros do Programa Saúde da Família no Rio de Janeiro. Rev Gaúch Enferm 2007;28(4):542-8.

3. Nauderer TM, Lima MADS. Práticas de Enfermeiros em Unidades Básicas de Saúde em Municípios do Sul do Brasil. Rev Latinoam Enferm [periódico na internet]. 2008 [acesso em 15 fev 2009];16(5). Disponível em: <www. eerp.usp.br/rlae $>$.

4. Alves VS. Um modelo de Educação em Saúde para o Programa de Saúde da Família: pela integralidade da atenção e reorientação do modelo assistencial. Interface Comunic Saúde Educ 2004/2005;9(16):39-52.

5. Costa, CHL. Histórico sobre a implantação do PACS e PSF no Estado do Pará. Rev Bras Enferm 2000;53(nº esp):131-3.

6. Ministério da Saúde (Brasil), Departamento de Atenção Básica. Histórico Cobertura SF Unidades. [homepage na internet]. [acesso em 25 maio 2010]. Disponível em: $<$ http://dab.saude.gov.br/atencaobasica.php >

7. 7.Secretaria Municipal de Saúde de Santarém (Brasil). Relatório de Gestão 2008. Santarém: SMS; 2009. p. 104.

8. Mendes Gonçalves RB. Práticas de Saúde: processos de trabalho e necessidades. São Paulo: CEFOR; 1992. p. 53.

9. Almeida MCP, Rocha SMM, organizadores. O Trabalho em Enfermagem. São Paulo: Cortez; 1997.

10. Peduzzi M, Anselmi ML. O processo de trabalho de enfermagem: a cisão entre planejamento e execução do cuidado. Rev Bras Enferm 2002;55(4):392-8.

11. Vasconcelos EM, organizadores. A saúde nas palavras e nos gestos: reflexões da rede de educação popular e saúde. São Paulo: HUCITEC; 2001.

12. Minayo MCS. O desafio do conhecimento: Pesquisa Qualitativa em Saúde. 11. ed. São Paulo: HUCITEC; 2008. p. 407.

13. David HMSL, Acioli S. Mudanças na formação e no trabaIho de enfermagem: uma perspectiva da educação popular e de saúde. Rev Bras Enferm 2010;63(1):127-31.

14. Wendhausen A, Saupe R. Concepções de educação em saúde e a estratégia de saúde da família. Texto \& Contexto Enferm 2003;12(1):17-25.

15. Acioli S. A prática educativa como expressão do cuidado em Saúde Pública. Rev Bras Enferm 2008; 61(1):117-21.

16. Cortez EA, Tocantins FR. Em busca de uma visão antropológica no Programa de Saúde da Família. Rev Bras Enferm 2006;59(6):800-4.

17. Marques D, Silva EM. A enfermagem e o Programa Saúde da Família: uma parceria de sucesso?. Rev Bras Enferm 2004;57(5):545-50.

18. Albuquerque PC, Stotz EM. A educação popular na atenção básica à saúde no município: em busca da integralidade. Interface Comun Saúde Educ 2004;8(15):259-74.

19. Villa E. Educação em Saúde: a prática educativa no cotidiano do trabalho do profissional. In. Gazzinelli MF, Reis DC, Marques RC, organizadores. Educação em Saúde: teoria, método e imaginação. Belo Horizonte: UFMG; 2006. p. 43-51.

20. Vasconcelos EM. Educação Popular nos serviços de saúde. 2. ed. São Paulo: HUCITEC; 1989. p. 139. 